\title{
Effect Of The Engine Speed And Loading On The Heat Transfer Within Exhaust Valves
}

\author{
Mahfoudh Cerdoun ${ }^{1, *}$, Bouziane Farsaoui ${ }^{1}$, Smail Khalfallah ${ }^{1}$, Rafik Lankri ${ }^{1}$, Carlo Carcasci ${ }^{2}$ \\ ${ }^{1}$ Laboratory of turbomachinery, Ecole Militaire Polytechnique, BP17 Bordj-el-bahri, Algiers, Algeria. \\ ${ }^{2}$ Department of Industrial Engineering - University of Florence - Via Santa Marta, 3 -Florence, Italy.
}

\begin{abstract}
The aim of the present paper is to investigate numerically the heat transfer within exhaust valves by considering the actual boundary conditions provided from an internal combustion engine at different load and speed. For this purpose, the valve is subdivided into seven adequate subdivisions to better assess the effect of each engine parts, therefore, an average value of the transient heat transfer coefficient (HTC) and the adiabatic wall temperature (AWT) for each subdivisions are evaluated during one cycle. These two parameters are introduced as boundary condition in a FEM model. The simulations are done at diverse engine regime, and therefore, the trend of the real boundary condition in term of HTC and AWT are given versus engine speed at different load. The findings show that the HTC increases linearly with engine speed however, the AWT decrease slightly at partial load and increase in the case of full engine load. The obtained model is used to highlight the temperature map, which will certainly help to avoid any damage to the exhaust valve.
\end{abstract}

\section{Nomenclature}

\begin{tabular}{|c|c|c|c|}
\hline$a$ & Constant & $\operatorname{Re}$ & Reynolds number \\
\hline$A$ & Area $\left(\mathrm{m}^{2}\right)$ & $T_{a}$ & $\begin{array}{l}\text { Adiabatic } \\
\text { temperature(K) }\end{array}$ \\
\hline$B$ & Bore diameter $(\mathrm{m})$ & $T$ & Temperature $(\mathrm{K})$ \\
\hline$D_{h}$ & $\begin{array}{l}\text { Hydraulic } \\
\text { diameter(m) }\end{array}$ & V & Velocity $(\mathrm{m} / \mathrm{s})$ \\
\hline$D_{m}$ & $\begin{array}{l}\text { Mean valve } \\
\text { diameter }(\mathrm{m})\end{array}$ & $V_{p}$ & mean piston speed $(\mathrm{m} / \mathrm{s})$ \\
\hline$D_{p}$ & Port diameter $(\mathrm{m})$ & $V_{s}$ & swept volume $\left(\mathrm{m}^{3}\right)$ \\
\hline$D_{s}$ & Stem diameter $(\mathrm{m})$ & $w$ & Seat width \\
\hline$L$ & Length $(\mathrm{m})$ & \multicolumn{2}{|c|}{ Greek symbols } \\
\hline$L_{v}$ & Valve lift (m) & $\alpha$ & Flow angle (deg) \\
\hline$\dot{m}$ & Mass flow & $\beta$ & Seat angle (deg) \\
\hline $\mathrm{Nu}$ & Nusselt number & \multicolumn{2}{|c|}{ Abbreviation } \\
\hline$P$ & $\begin{array}{l}\text { specific pressure } \\
\left(\mathrm{N} / \mathrm{m}^{2}\right)\end{array}$ & HTC & $\begin{array}{l}\text { Heat transfer coefficient } \\
\left(\mathrm{W} / \mathrm{K} \cdot \mathrm{m}^{2} .\right)\end{array}$ \\
\hline $\mathrm{Nu}$ & Nusselt number & TCC & $\begin{array}{l}\text { Thermal contact } \\
\text { conductance }\end{array}$ \\
\hline
\end{tabular}

\section{Introduction}

The valves of an internal combustion engine (ICE) play an important role in the automobile field since any failure on the heat transfer affects the engine performance

\footnotetext{
Corresponding author: Cerdoun.mahfoudh@gmail.com
}

and the volumetric efficiency. Recently, the continuous demands for lowest fuel costs and engine downsizing have resulted in progressively more arduous conditions in particular for the exhaust valve. The heat transfer through valves not only changes with engine conditions but also is constantly changing during each part of the four-stroke engine cycle.

The details of the flow through the exhaust/intake portvalve-cylinder are widely studied in the first half of last century $[1,2]$. Based on simplified laboratory test rig, a lot of researchers tried to find correlations that describe the transfer around the valve. But their major drawbacks are the ignorance of the real operation condition of such valves. Stotter et al. [3] used separate forms of the empirical equations for turbulent pipe flow to estimate the heat transfer to the seat region by $\mathrm{Nu}=0.02 \mathrm{Re}^{0.8}$ and the remaining region of the valve surface $^{\mathrm{Nu}}=\left(0.005+0.09\left(\mathrm{~L}_{\mathrm{v}} / D_{\mathrm{v}}\right)^{0.8}\right) \operatorname{Re}^{0.8}$ where $L_{\mathrm{v}}$ and $D_{\mathrm{v}}$ represent the valve lift and diameter, respectively. Annand and Lanary [4] focused their study on the measuring of the end thrust on a valve model. The aerodynamic end thrust on a poppet valve is closely equal to the product of the overall pressure drop and the exposed head area at a small lift and the trusts fall progressively when valve lifts exceeding about 0.15 times the seat diameter. Kastner et al. [5] carried out both steady 
and unsteady-flow tests on inlet valves of different geometry demonstrating that by including radii on various corners of the valve and its seat the performance of the valve was improved.

The results of the steady-flow tests were presented in the form of discharge coefficients, the reference area was a function of valve lift and it was described by three equations. Given the location of the valve and their working conditions, the experimental studies seem very complicated. Woschni [6] considered only the seat.

He applied the equation for turbulent heat transfer in the entrance region of a two-dimensional channel and he gave he Nusslet number by $\mathrm{Nu}=0.004\left(L_{\mathrm{v}} / D_{\mathrm{v}}\right)^{-0.2}\left[1+0.206\left(L_{\mathrm{v}} / D_{\mathrm{v}}\right)^{0.75}\right] \mathrm{Re}^{0.8}$

- Contrariwise, Annand [7] estimated the heat transfer coefficient around all an idealized poppet-type valve, it can be represented by $\mathrm{Nu}=\mathrm{a} \mathrm{Re}^{0.58}$ where the factor a is a function of lift/diameter ratio. This correlation, of course, ignored the engine load, fluid cooling, sparks timing effects and tiled some real conditions surrounding the valve but it drew an experimental way to assess the valve temperature. Todinson et al. [8] presented a method basing on the average gas temperature during the engine cycle for assessing the maximum temperature of exhaust valves in internal combustion engines. Shojaefard et al. [9] developed a methodology for transient thermal analysis of the exhaust. The model includes exhaust valve, seat, guide, and spring. They found that the maximum thermal stress is developed at the valve seat contact zone. Recently, Cerdoun et al. $[10,11]$ presented a numerical approach to assess the temperature map of an exhaust valve, based mainly on the basic concept of heat transfer and available correlations. They conclude that the boundary conditions implemented as an average of HTC and adiabatic wall temperature are shown to underestimate the temperature, whereas cyclic boundary condition required more run time to reach steady state.

In the present paper, the effect of the load and engine speed on the heat transfer within exhaust valves is investigated numerically. The main contributions of the present paper are to perform the numerical approach presented by Cerdoun et al. [10,11], which concerns an exhaust valves by considering the relative motion of the valves and flow transition inside the exhaust manifolds and to estimate the heat transfer coefficients and adiabatic wall temperature at divers engine speed and at various load

\section{Numerical approach}

\subsection{Methodology and Valve geometry subdivision}

In order to resolve the heat transfer equation of conduction through valve, the boundary condition could be, first, defined. Available correlations and basic knowledge in the heat transfer are used to quantify the boundary conditions.

The instantaneous convective heat flux $q(\mathrm{t})$ can be written as:

$$
q(t)=H T C(t) \cdot A \cdot\left[A W T(t)-T_{w}(t)\right]
$$

Where $\operatorname{HTC}(t)$ is heat transfer coefficient and $\mathrm{A}$ is the exposed area. $\mathrm{T}_{\mathrm{w}}(\mathrm{t})$ the instantaneous wall temperature and the adiabatic wall temperature $\mathrm{AWT}(\mathrm{t})$ is the temperature that would be the wall temperature without any heat transfer, which would be also the fluid temperature near the wall.

An average value of convective heat flux may be defined from the previous equation

$$
\bar{q}=\bar{h} \cdot A \cdot\left[\overline{T_{a}}-\overline{T_{w}}\right]
$$

During a period $\mathrm{T}$, the average value of the heat flux, heat transfer coefficient and wall temperature are defined by:

$$
\left\{\begin{array}{l}
\bar{q}=\frac{1}{T} \int_{0}^{T} h(t) \cdot A \cdot\left[T_{a}(t)-T_{w}(t)\right] d t \\
\overline{T_{w}}=\frac{1}{T} \int_{0}^{T} T_{w}(t) d t \\
\bar{h}=\frac{1}{T} \int_{0}^{T} h(t) d t
\end{array}\right.
$$

A definition of the average adiabatic wall temperature is deduced by a combination of the system (3) with eq. 2 as following:

$\overline{T_{a}}=\frac{1}{\bar{h} T} \int_{0}^{T} h(t) \cdot T_{a}(t) d t$

The average values of adiabatic wall temperature and heat transfer coefficient are used as boundary condition of a steady FEM model in the aim of highlighting the temperature valve distribution. To well carry out this investigation, an appropriate subdivision considering the different parameters that affect the heat transfer through valve is imposed. Such subdivision may help to better identify and quantify the boundary condition. A subdivision based on the position of the exhaust valve during the engine cycle and the surrounding block engine geometry seems fitting since the instantaneous variations of the fluid property is taking into account. Seven zones are considered in the present study:

a) Combustion face constitute by the valve part revolt versus the internal cylinder, delimitate by the maximum diameter between valve and seat, it may be treated as part of chamber combustion.

b) Seat. The contact valve -seat constitute 3/4 of time of one cycle and the main heat is being dissipated when exhaust valves are closed.

\footnotetext{
* Corresponding author: Cerdoun.mahfoudh@gmail.com
} 
c) Stem-port. This part of valve stem is located in the exhaust manifold during all the engine cycle; it is exposed to the burned gas.

d) Stem-guide. Part of stem witch mate with the guide, it is exposed to the heat transfer cooling.

e) Stem-tip. End of valve located in train-cam system.

fStem port/guide. Depending on the valve lift, this part is located in intermediate between the two zones stem-port and stem-guide. Their length is totally include in the exhaust port when the lift is at its maximum and totally mate the guide when the valve is closed.

g) Stem guide/tip. This part is located in intermediate between the stem guide and the stem_tip.

\subsection{Assignment of the Boundary Conditions}

\subsubsection{HTC Valve head}

_Many correlations were available to predict the heat fluxes and temperatures in internal combustion engines. From their experimental setup, Shayler et al. [12] concluded that Woschni's [13] correlation presents best agreement, thus, Woschni's correlation is used in the present study (see table $1)$.

\subsubsection{HTC valve seat}

In this paragraph, a significant attention has been given to this zone to include all aspects thus influencing the heat transfer and the developed method can be applied to both exhaust and intake valve.

\subsubsection{HTC valve-seat: valve open:}

The mass flow rate through both the inlet and exhaust valves is approximately given by the equations for compressible flow through a flow restriction.

$$
\dot{m}=\frac{c_{d} A_{R} P_{0}}{\left(R T_{0}\right)^{\frac{1}{2}}}\left(\frac{p_{T}}{p_{0}}\right)^{1 / \gamma}\left\{\frac{2 \gamma}{\gamma-1}\left[1-\left(\frac{p_{T}}{p_{0}}\right)^{(\gamma-1) / \gamma}\right]\right\}^{1 / 2}
$$

Thus, Reynolds number is

$$
R e=\frac{c_{d} D_{h} P_{0}}{\mu\left(R T_{0}\right)^{\frac{1}{2}}}\left(\frac{p_{T}}{p_{0}}\right)^{\frac{1}{\gamma}}\left\{\frac{2 \gamma}{\gamma-1}\left[1-\left(\frac{p_{T}}{p_{0}}\right)^{\frac{\gamma-1}{\gamma}}\right]\right\}^{\frac{1}{2}}
$$

The heat transfer coefficient used for each rang of Reynolds number and lift value are taken from [11].

\subsubsection{HTC valve-seat: valve close:}

The determination of heat transferred from the exhaust valve to its seat requires the involvement of the complex geometry and the thermos-physical characteristic of all the material of the cylinder head. The theoretical model suppose that the heat flow path for each medium look alike a truncated cone, thus the total resistance of the thermal equivalent circuit model for this evening can be deduced (see Table 1)

\subsubsection{HTC valve stem_porte}

\footnotetext{
* Corresponding author: Cerdoun.mahfoudh@gmail.com
}

The flow in the port is inclined from the stem axial about an angle imposed by the port shape. Carcasci et al. [14] modeled that situation as the sum of heat transfer around cylinder and parallel to flat plat since the HTC for those situation are available in the open literature ( see Table 1). One may use a weighting coefficient $(\epsilon \in[0,1])$ to favor one geometry against the other.

\subsubsection{HTC stem guide}

The heat transfer in the zone stem guide can be assumed to a typical conduction through multilayer cylinder. However the transition from real model to theoretical one incorporate the effect of lubricating oil and the contact resistance between the guide and the engine block since that editing is realized by forced assembly (see Table .1)

\subsubsection{HTC stem tip}

The cyclic motion of valve takes place with the help of a rocker lever connected to a push rod which rests over the cams on a camshaft. The tip of valve is exposed to air and by ignoring friction between the stem tip and the cams system, a fixed value is assigned to HTC.

\subsubsection{HTC stem guide/port}

Relating to the law valve motion, this area is exposed to both condition of the guide and the port zone. Figure 1 explains the different cases may be taken by the valve during one cycle. When the valve is closed, the totality of this zone is include in guide, thus, the heat transfer coefficient is the heat transfer coefficient of zone guide. When the valve reaches his lift maximum,, the totality of this zone is included in the port, thus, the heat transfer of the zone stem_port will be attributed.

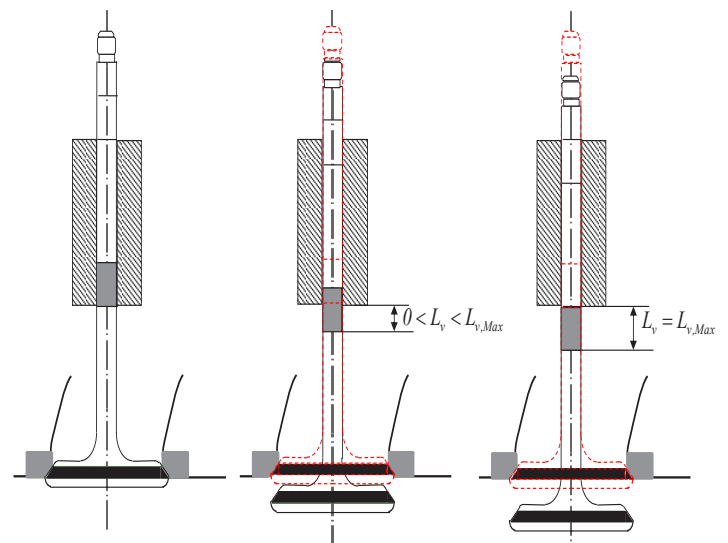

Figure 1: Thermal analyses of the zone stem guide/port.

\subsection{HTC stem guide/tip.}

This part of stem is initially out (valve close) of the guide and during the valve opening, a part of this zone enter gradually to the guide, until the totality of this zone will be include in the guide and its maximum length which of course correspond to the maximum of lift. The same way as stem_guide/port zone is used to obtain the instantaneous heat transfer coefficient. 
Table 1: Assignment of the boundary conditions for different zones

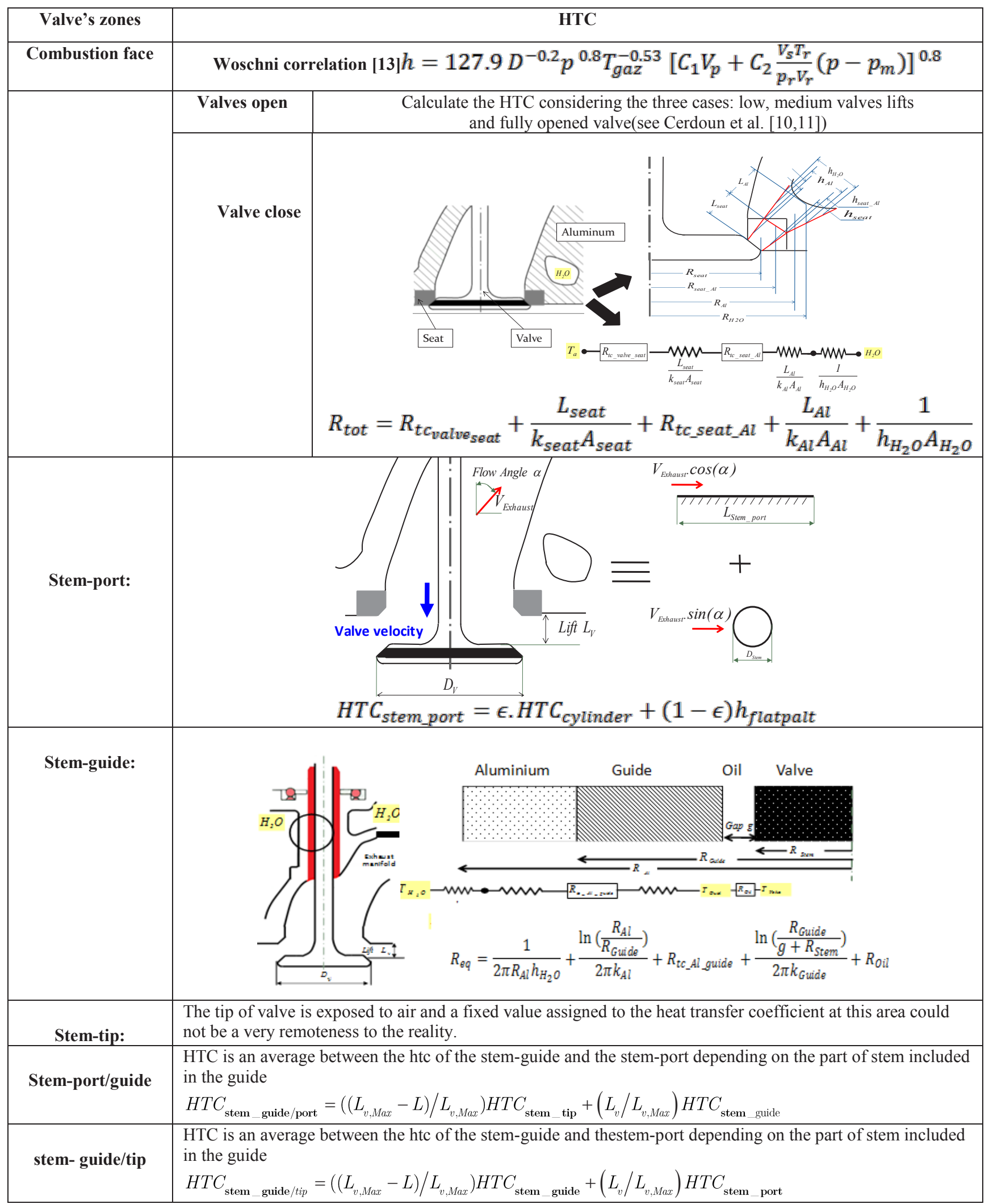

\footnotetext{
* Corresponding author: Cerdoun.mahfoudh@gmail.com
} 


\section{Application to an exhaust valve}

\subsection{Model of the diesel engine}

The exhaust valve is mounted in 5.9L 24 valves diesel engine equipped with a turbocharger, the model is presented in the tutorial of the Ricardo Wave software is used [15]. The diesel engine is six cylinder and the firing order for the engine is 1-5-3-6-2-4, with the cylinders 1 through 3 exhausting into the hub-side entry volute and the cylinders 4 through 6 exhausting through the shroud-side entry of volute. The specifications for the engine are given in Table 2.

Table 2: Diesel Engine Specifications

\begin{tabular}{|c|c|}
\hline Parameters & Values \\
\hline Configuration & Inline 5.9L, 6 Cyl. Diesel engine \\
\hline Bore & $102 \mathrm{~mm}$ \\
\hline Stroke & $120 \mathrm{~mm}$ \\
\hline Connecting rod length & $200 \mathrm{~mm}$ \\
\hline Valve train & 4 Valves per cylinder \\
\hline Compressor Ratio & 17 \\
\hline Firing order & 15624 \\
\hline
\end{tabular}

Figure 2 presents the 1D Schematic model for the whole engine piping system used by Ricardo Wave. The engine module is comprised of multiple engine cylinder modules linked with the external component modules, such as manifolds, compressors and turbines, heat exchangers, air filters, and exhaust system elements. The engine cylinder model tracks the thermodynamic processes within the cylinder throughout a cycle function of the crank angle. By the use of ducts and junctions to model the physical geometries of the diesel engine with an appropriate discretization, WAVE then solves the governing partial differential equations by the finite difference approach. The 1D model of the diesel engine is capable to provide all thermodynamics parameters necessary to calculate the boundary condition.

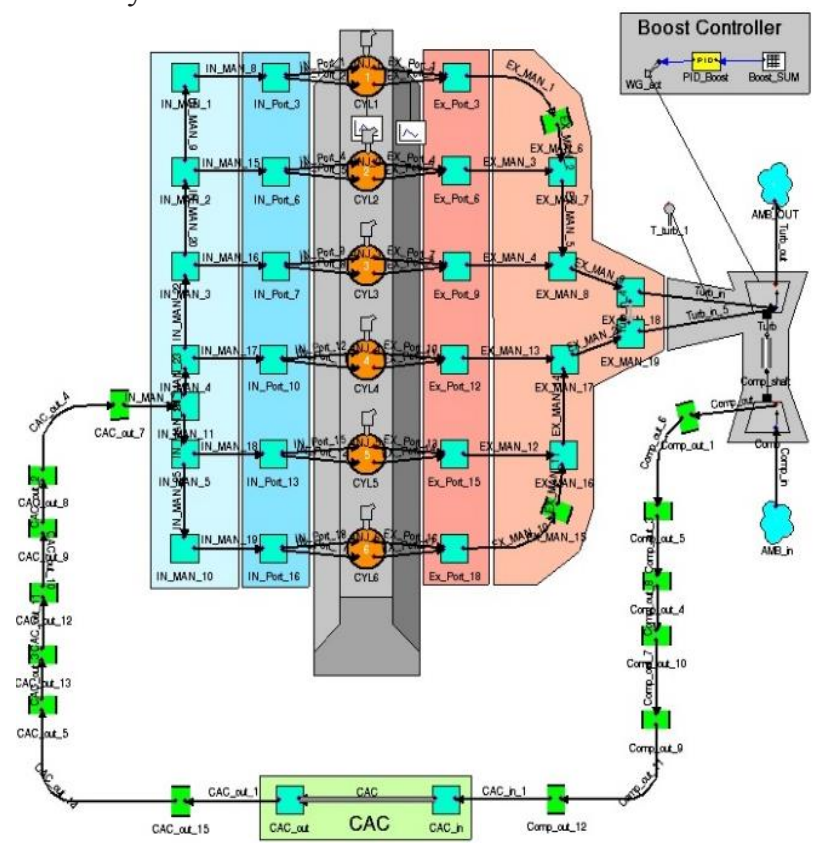

Figure 2: Schematic of the WAVE model

\subsection{Valve geometry}

The geometry of the exhaust valve is shown in Figure 1. The exhaust valve sits on the cylinder head of a combustion chamber. The engine coolant liquid passes around the cylinder liner and the water passages in the cylinder head. The valve pops up and down to let the exhaust gases leave the combustion chamber.

Table 3: Valve head geometry

\begin{tabular}{|c|c|}
\hline Seat length & $4.20 \mathrm{~mm}$ \\
\hline Mean stem diameter & $7.94 \mathrm{~mm}$ \\
\hline Mean valve diameter & $41.57 \mathrm{~mm}$ \\
\hline Maximum lift & $10.445 \mathrm{~mm}$ \\
\hline Valve length & $112 \mathrm{~mm}$ \\
\hline Seat angle & $45^{\circ}$ \\
\hline
\end{tabular}

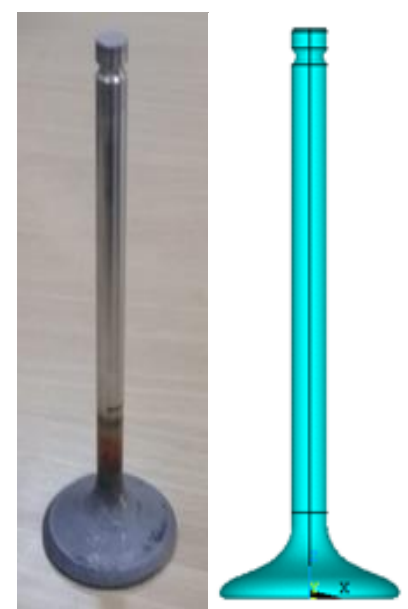

Figure 3: Real and CAD Valve gemetry

\subsection{The finite element analysis}

In this work, due to the geometric symmetry of valve and free freedom rotation of the valve around its axis, the model is studied in two dimensions. Then, the FEM is established using ANSYS software. The 2-D 4-node thermal plane element PLANE55 is applied to mesh the whole valve and in order to obtain a better results a refinement is applied near the curvature line (Figure 4).

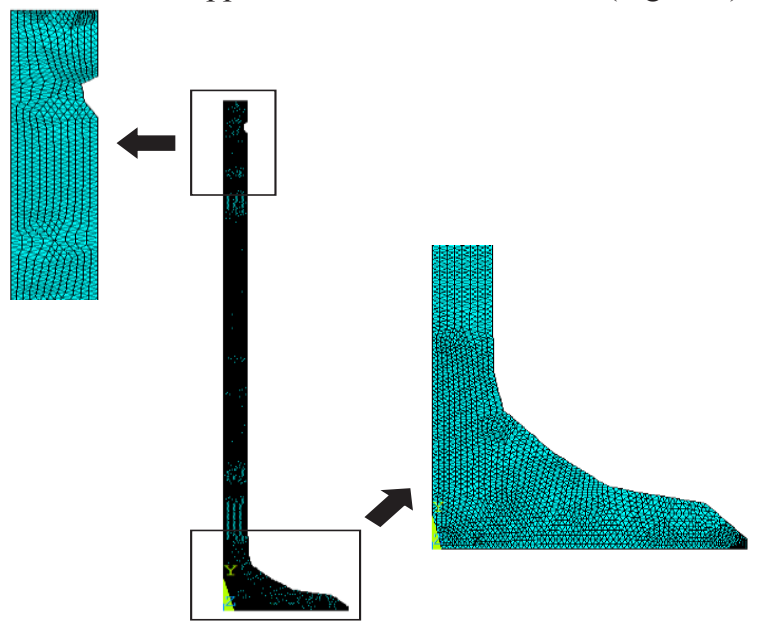

Figure 4: Finite-element model of the exhaust valve

To facilitate simulation runs of the proposed model an APDL (ANSYS Parametric Design Language) code is developed. The triangular element is chosen to create the 
meshing. The average values of the instantaneous heat transfer and the adiabatic wall temperature of each zone are calculated and they includes as steady boundary condition in the FE model. By varying the element size distribution inside valve, five different triangle meshes were generated. The maximum temperature of the exhaust valve obtained for various size of the meshes enabled to retain an average grid about 1217 elements to carry out the simulations, since the maximum of temperature are relatively stable.

\section{Results and discussions}

\subsection{Boundary conditions for the exhaust valves}

Figure 5 presents the evolution of the HTC at diverse engine speed and at four different load $(25 \%, 50 \% 75 \%$ and $100 \%$ ). For the combustion face, the HTCs vary linearly per the engine speed per aslope of 0.6130 .539 , 0.290 and 0.179 for the four load $100 \%, 75 \%, 50 \%$ and $25 \%$, respectively. The same trend for the HTC as the combustion face is recorded for the stem port and the stem guide zones. However, for the case of the seat zone, the HTCs increase slightly with the rise of engine speed per slope of 0.1 at engine load of $25 \%$.For the three remained cases $(50 \%, 50 \%$ and $100 \%)$, the HTC follow a polynomial trend where it is shown that the HTCs drop at high engine speed.

For the four zones, it is well noted that the HTCs rises with the increase of the load mainly at the zones seat. At low engine speed of $1250 \mathrm{rpm}$, the HTC passes from 1159 $\mathrm{W} / \mathrm{Km} 2$ to $1433 \mathrm{~W} / \mathrm{W} / \mathrm{Km} 2$.

Figure 6, highlights the AWT at four zones for different engine regime. For the combustion face the AWT decreases with the engine speed principally at full engine speed. As the HTC for the seat zone, the AWT present a polynomial behavior whereas, for the two zones stem port and stem_guide, the AWT rise and present a linear behavior versus the engine speed.

The most significant factor in the performance of an exhaust valve is its operating temperature. The maximum temperature occurring within the exhaust valves is a one parameter to characterize the thermal. The importance of temperature can be valued by its effect on the physical properties of the valve. Figure 7 shows the maximum of the temperature recorded at various engine speeds and at various loads. It highlights that the maximum of the temperature of an exhaust valves is greatly affected by the increase of load.

At engine speed of $1800 \mathrm{rpm}$ and at full load, the temperature attains $912 \mathrm{~K}$ while at partial load of $25 \%$ it was $600 \mathrm{~K}$, significant of rise around 52\%.

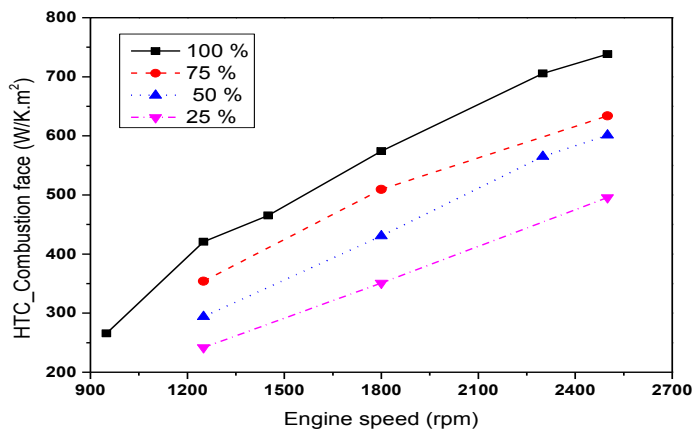

a)

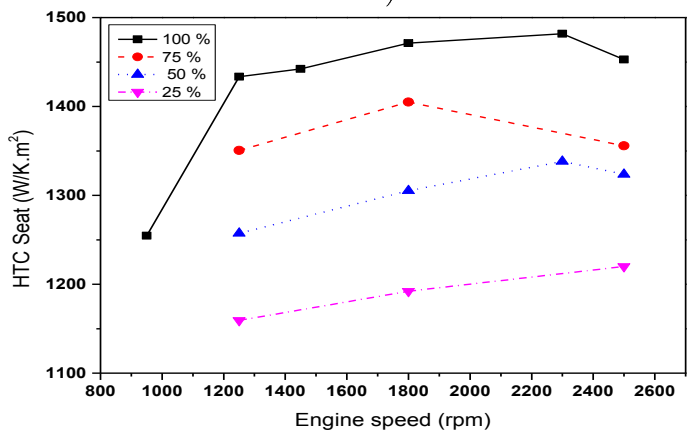

b)

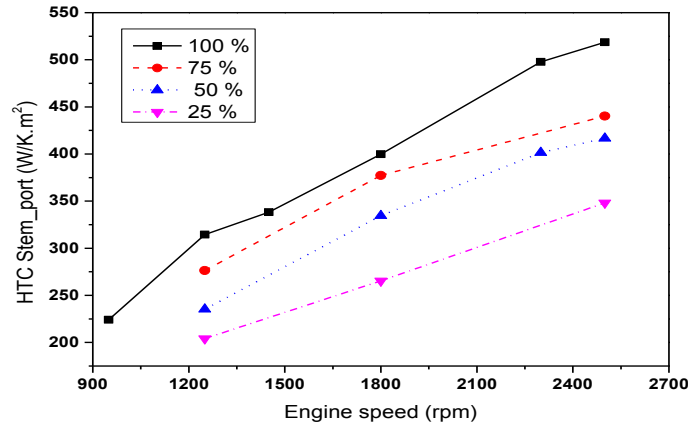

c)

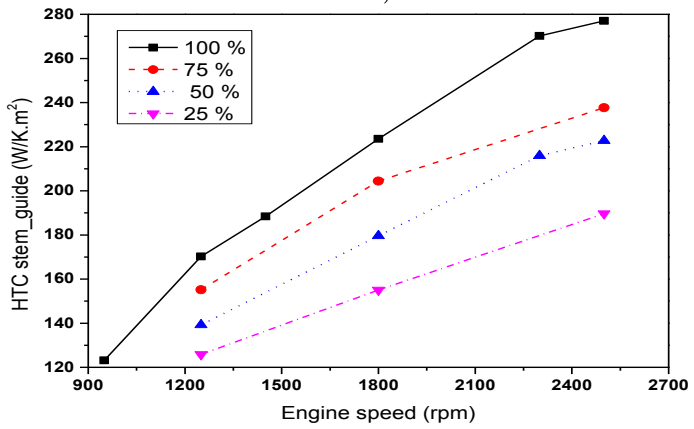

d)

Figure 5: The heat transfer coefficient at different loading versus the engine speed for the zones a) combustion face, $b$ ) seat, c) stem_port, and d) stem_guide

* Corresponding author: Cerdoun.mahfoudh@gmail.com 


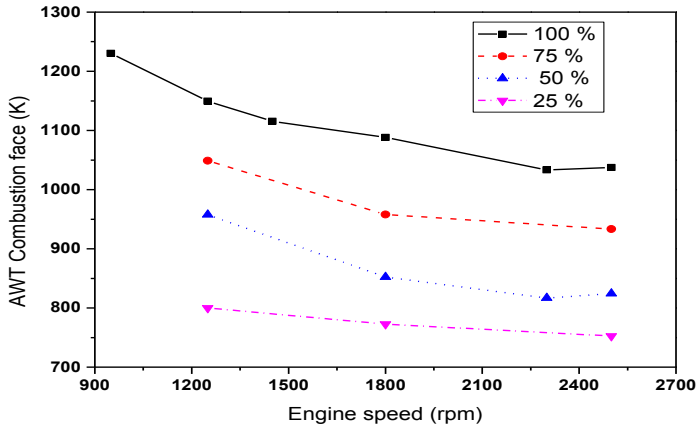

a)

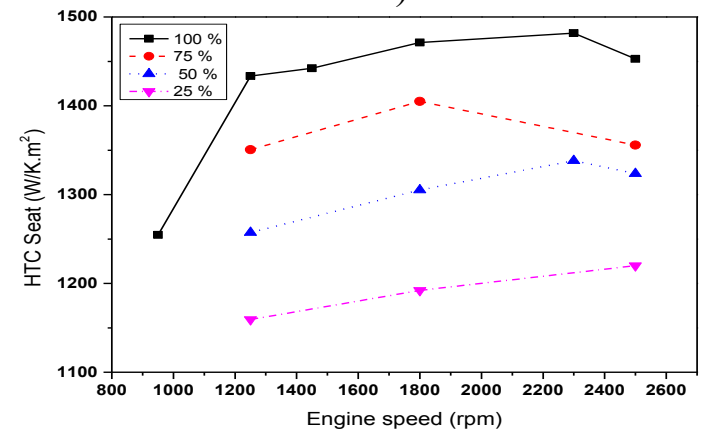

b)

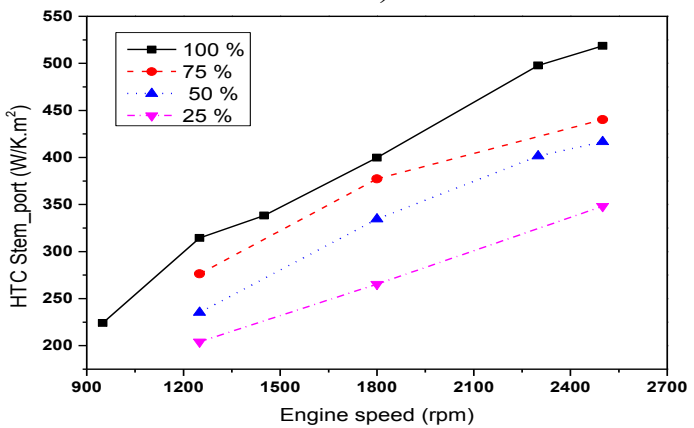

c)

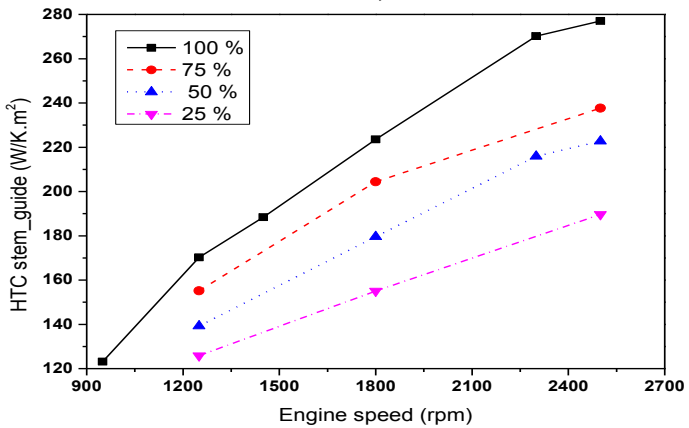

d)

Figure 6: Adiabatic wall temperature at different loading versus the engine speed for the zones a) combustion face, $b$ ) seat, c) stem port, and d) stem guide

This behavior is expected since the increase of load is synonyms of more fuel to be burned. It is also noted from figure 7 , that keeping the load constant, the maximum temperature is practically invariant due to slight difference between different cases in term of mass flow rate of the fuel. For example, at partial load of $75 \%$, the mass flow rate of the fuel is $18.31 \mathrm{~kg} / \mathrm{hr}, 24 \mathrm{~kg} / \mathrm{hr}$ and $26.86 \mathrm{~kg} / \mathrm{hr}$ at engine speeds of $1250 \mathrm{rpm}, 1800 \mathrm{rpm}$ and $2500 \mathrm{rpm}$, respectively.

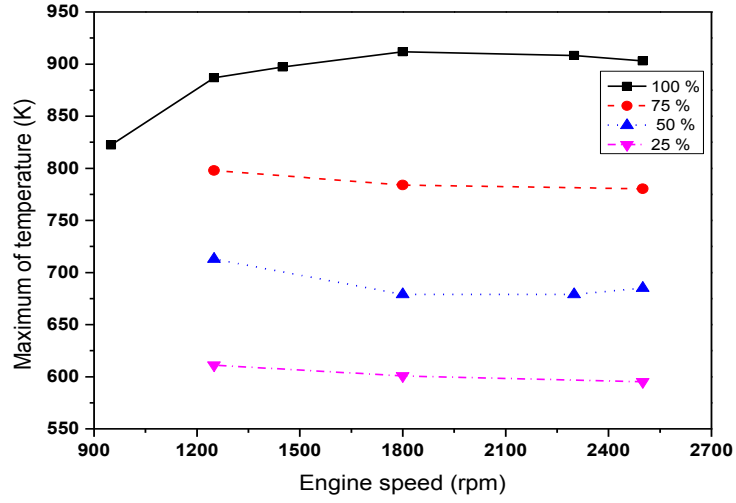

Figure 7: Evolution of the maximum temperature at diverse engine speeds and loads.

It is also important to expect the evolution of temperature within the exhaust valves at a fixed operating condition. Figure 8.a presents the actual seven subdivisions applied to the present exhaust valves and Figure 8.b shows the temperature evolutions for 9points that cover as possible the entire valve's subdivision. The valve is heated at the center ( $\mathrm{Pt} \mathrm{1,Pt} 3$ and $\mathrm{Pt} 4)$ and at the port $(\mathrm{Pt} 5)$ and less heated near the seat ( $\mathrm{Pt}-\overline{2}$ ) due to the cooling. The temperature over all the exhaust valve is quickly stabilizes before the first $50 \mathrm{~s}$.
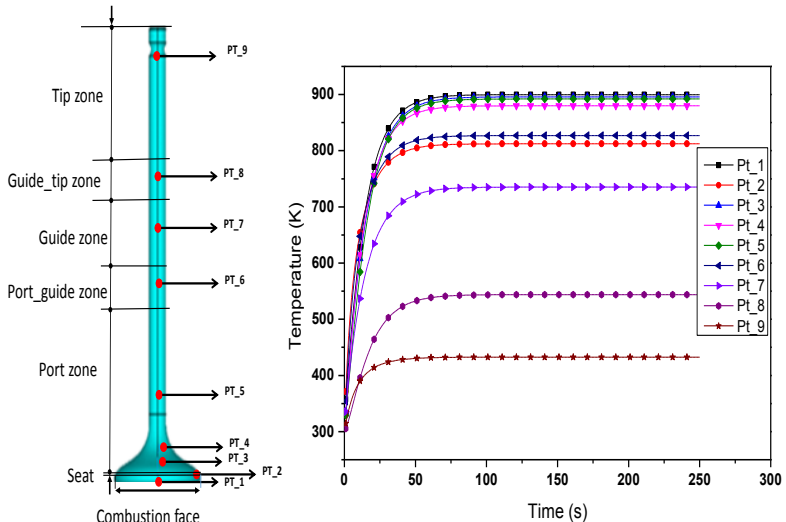

a)

b)

Figure 8: a) Exhaust valve subdivision and b) Temporal evolution of the 9 points in the valve

Figure 9.a shows the temperature map of the exhaust valve at the end of unsteady simulations $(250 \mathrm{~s})$ in addition, figure 9.b and 9.c show the thermal flux and thermal gradient. A maximum value of temperature about $904 \mathrm{~K}$ is recorded through the overall valve typically at the combustion face since it is directly exposed to the incylinder temperature. The vectors of thermal flux density are shown to be directed to the seat region in order to continuously remove the heat from the valve and thus avoid any damage to exhaust valve. The stem-port region the thermal flux density intensifies due to high difference between the stem-port region, which is exposed to exhaust gas, and the stem-guide region to the cooling fluid. It is clearly apparent that the zone labelled stem-guide/port located in between the two zones records a rapid decrease; therefore with the cyclic motion of the valve, this area is susceptible to a high thermal fatigue.

* Corresponding author: Cerdoun.mahfoudh@gmail.com 


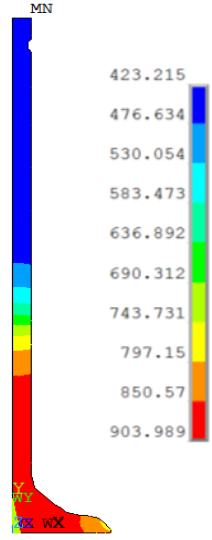

a)

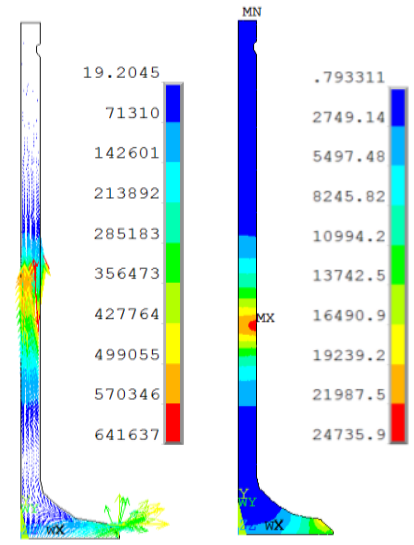

b) c)
Figure 9: Heat transfer analysis within valve in term of: a) Temperature map, b) Thermal flux and c) Thermal gradient

\section{Conclusion}

A simple numerical model performed in the present work for assessing the temperature map of both exhaust and intake valve, based upon the basic concept of the heat transfer and available correlation related to internal combustion engine. This model considers the actual operation conditions and therefore a better emphasize of the temperature distribution through valves. The HTC is found to increase linearly with engine speed valve for the zones labeled stem_port and stem_guide whereas for the seat zone, the HTC follow mainly a polynomial trend. Only for the combustion face the AWT decreases with the engine speed principally at full engine speed and present a polynomial behavior at the zone seat whereas, for the two zones stem port and stem guide, the AWT raise linearly versus the engine speed. The temperature map allows delimiting the zone labeled stem-guide/port which records a rapid decrease; this area is susceptible to a high thermal fatigue.

\section{Reference}

1. Zipkin,M.A, Sander, J,C, "Correlation of exhaust valve temeprature with engine operating condition and valve design in an air cooled cylinder", NASA report $\mathrm{n}^{\circ} 813,(1945)$.

2. Stanitz, T. D., Lucia, R. E., Masselle, F. L. 'Steady and intermittent flow through poppet intake valves', NACA tech. Note No. 1035, (1946).

3. Stotter, A., Woolley, K. S. Ir, E. S. 'Exhaust valve temperature - a theoretical and experimental investigation', S.A.E. Trans. 74, 89, (1966).

4. Annand W. J. D, Lanary ,R. S, "Heat transfer measurements on a simple model representing a poppet exhaust valve in an out flowing stream" Journal mechanical engineering science, Vol, 12, No, 3, (1970).

5. Kastner L. J, Williams, T. J., and White, J. B.: "Poppet Inlet Valve Characteristics and Their influence on the Induction Process" Proc. Instn Mech. Engrs, vol. 178, pt. 1, no. 36, pp. 951-978, 1963-196, (1963).

\footnotetext{
* Corresponding author: Cerdoun.mahfoudh@gmail.com
}

6.Woschni, G. 'Electronic calculation of the time curve of pressure, temperature and mass flow rate in the cylinder of a diesel engine', Computers in internal combustion engine design, Proc. Instn mech. Engrs 1967-68 182 (Ft 3L), 71. (1967)

7. Annand, W. J. D.Heat transfer in the cylinders of reciprocating internal combustion engines. Proc. Instn Mech. Engrs, 1963,177(36), 973-99, (1963)

8. Todinson G. R., Leonard, R. Henshal S. H. , "research note: a method for assessing the maximum temperature of exhaust valves in internal combustion engines" Journal Mechanical Engineering Science, IMechEVol 16 No 4 (1974).

9. M. H. Shojaefard, A. R. Noorpoor , D. A. Bozchaloe\& M. Ghaffarpour, Transient Thermal Analysis of Engine Exhaust Valve, Numerical Heat Transfer, Part A:Applications: An International Journal of Computation and Methodology, 48:7, 627-644, (2005)

10.Cerdoun M., Carcasci C., Ghenaiet A., An Approach for the Thermal Analysis of Internal Combustion Engines' Exhaust Valves, Applied Thermal Engineering, j.applthermaleng.2016.03.105, (2016)

12. Cerdoun M., Carcasci C., Ghenaiet A., "Analyses of unsteady heat transfer of internal combustion engines exhaust valves" J. of engine research (2018).

12. Shayler, P. J., Colechin M. J. F. and Scarisbrick, A., Heat Transfer Measurements in the Intake Port of a Spark

13. Woschni, G.A universally applicable equation for the instantaneous heat transfer coefficient in the internal combustion engine. SAE paper 670931, (1967)

14. Carcasci, C., Facchini, B., 1996; "A Numerical Procedure to Design Internal Cooling of Gas Turbine stator Blades", Revue Générale de Thermique (now: Int. J. of Thermal Sciences), Vol. 35, n. 412 Aprile, pp.257-268. (1996).

15. Ricardo WAVE 8.0 Tutorial (2012) 